\title{
Assessment of physicians' knowledge, attitudes, and practices regarding smoking cessation management in the Gaza Strip
}

\author{
Khaled Hani Alkhodari1*, Bakr Khadr Abo Jarad'1, Ahmed Ismail \\ Al-Bahbhani ${ }^{1}$, Sadi Yehia Nkhala ${ }^{1}$, Ali Naim Al-Buhisi ${ }^{1}$ and \\ Khamis Abdelkarim Elessi² \\ ${ }^{1}$ Medical Doctor, Al-Shifa Hospital, Gaza Strip, Palestine \\ ${ }^{2}$ Associate Professor and Head of EBM, Faculty of Medicine, Islamic University of Gaza, Gaza Strip, \\ Palestine
}

\section{Abstract}

Background: Despite its negative effects, approximately $23 \%$ of Palestinians ( $\geq 18$ years) smoke cigarettes. Studies have shown physicians to be an important channel for smoking cessation intervention. This investigation examines physicians' smoking-related knowledge, attitudes, and behaviors in the Gaza strip (Palestinian Territories).

Methods and findings: A convenience sample of 154 physicians in medical and surgical units took part in this investigation ( $87.7 \%$ response rate). The data show that $37.8 \%$ of physicians in Gaza smoke, and most of them about $72 \%$ smoke in the hospital's public spaces, thereby implicitly giving public approval for smoking. While $82.4 \%$ reported that they advise patients who smoke to stop, the majority (59\%) also believe that their own smoking habits negatively influence the impact of that advice.

Unfortunately, our survey showed that physicians' knowledge levels towards smoking addiction and management were lower than expected (e.g. only $34 \%$ knew that nicotine dependence is a psychiatric disorder that necessitates treatment). The physicians in this study believed that the primary barriers to failure of their patients' smoking cessation were the perceived lack of will (81.3\%), and the strength of patients' addiction (67.9\%). Moreover, (61\%) of physicians did not spend enough time to convince their patients to quit smoking.

Conclusion: Smoking is common among Gaza-strip physicians, and unfortunately, most of them smoke in the hospital's public spaces. Many obstacles face the smoking cessation program that some physicians linked it to patients, and others linked it to the health-care system. Furthermore, smokers in Gaza receive poor care regarding assessment, referral, and management of their smoking habit.

\section{More Information}

*Address for Correspondence: Khaled Hani Alkhodari, Medical Doctor, Al-Shifa Hospital, Gaza Strip, Palestine, Tel: +00970599303107; Email: khaled.alkhodari@gmail.com

Submitted: 08 January 2020

Approved: 10 February 2020

Published: 11 February 2020

How to cite this article: Alkhodari $\mathrm{KH}$, Jarad BKA, Al-Bahbhani Al, Nkhala SY, Al-Buhisi AN, et al. Assessment of physicians' knowledge, attitudes, and practices regarding smoking cessation management in the Gaza Strip. J Addict Ther Res. 2020; 4: 001-005.

DOI: dx.doi.org/10.29328/journal.jatr.1001010 ORCiD: orcid.org/0000-0002-1537-9717

Copyright: @ 2020 Alkhodari KH, et al. This is an open access article distributed under the Creative Commons Attribution License, which permits unrestricted use, distribution, and reproduction in any medium, provided the original work is properly cited.

\section{Check for updates}

OPEN ACCESS

\section{Introduction}

According to a systemic analysis of the global burden of disease (2015), the population's exposure to smoking decreased in many countries, as well as globally. Moreover, global tobacco-attributable deaths and disability-adjusted life-years (DALYs) continued to rise, to be the second most common cause of global DALYs [1]. Furthermore, smoking resulted in more than 7 million deaths worldwide annually, and smoking-related diseases claim more lives than HIV/ AIDS, malaria, and tuberculosis combined [2].
Consistent with these worldwide mortality data, data from 2010 showed lung cancer (of which smoking is a leading cause) is nearly the most common type of cancer in Palestine $(10.8 \%$ of all cancer cases), with cancer emerging as the second leading cause of mortality among Palestinians that is about $12.5 \%$ of all death cases. In addition, passive smoking was a major threat to respiratory health in children, the primary cause of low birth weight, and a likely cause of sudden death among infants [3].

Physicians can play a key role in efforts to reduce smoking 
by using their unique professional privilege [4-6]. They gain this privilege from their close contact with the public, and the fact that they can play as role models, opinion leaders and often decision-makers for healthcare policies [5]. Physicians not only can advise a smoker to quit but also they can contribute to global smoking cessation programs by using more intensive interventions; such as counseling or pharmacologic therapy [4]. At the organizational level, smoke-free hospitals and physician support for such policies have shown to improve patient and healthcare worker health, and it is a part of an overarching effort to promote smoking cessation [7,4]. Indeed, physician smoking cessation programs have found to be both efficacious and cost-effective for patient smoking outcomes [8]. Specifically, a systemic review found that a brief advice intervention to smokers increases cessation rates by one to three percent [9].

This investigation examines physician smoking-related attitudes, knowledge, and behaviors in Gaza -strip in Palestine. The Palestinian Central Bureau of Statistics (PCBS) has estimated the percentage of smokers among Palestinians older than 17 years to be approximately 23\% (26.9\% in West Bank compared to $15 \%$ in Gaza Strip) [3], which is similar to the global prevalence of $22 \%$ issued by the WHO in 2010 [10]. Unfortunately, there is little data available to healthcare policymakers that would help them assess the need for a physician-led smoking cessation program for patients.

\section{Methods}

A descriptive study aimed to assess physicians' knowledge, attitude, and behaviors regarding smoking cessation strategies in Gaza Strip hospitals (Al-Shifa hospital (SH), European Gaza Hospital (EGH), Nasser hospital (NH), and Al-Aqsa hospital (AH)). The target population included 616 physicians who work in all medical and surgical departments in these hospitals. A stratified sampling into internists and surgeons was done, and it is followed by a convenience sampling of 154 physicians, of which 135 (87.7\%) participated in the investigation. The greatest percentage of participating physicians was from Al-Shifa hospital (51\%), and the fewest from Al-Aqsa hospital (9\%). Additionally, 35.5\% $(n=48)$ of physicians were from internal medicine departments, and $64.4 \%(n=87)$ were surgeons. Most of the candidates were consultants (42\%), and specialists (31\%) (Table 1).

Participating physicians completed a self-structured questionnaire that was divided into four parts: measures of personal smoking behaviors, measures of physician perceptions of patient smoking habits, measures of patients' smoking cessation efforts, and smoking cessation barriers from physicians' point of view. Some of the tool's items were gathered from the Royal Australian College of General Practitioners (RACGP): supporting smoking cessation: a guide for health professionals in 2014 [11]. The gathered items were mainly related to the barriers that face smoking cessation management and the management of smoking

\begin{tabular}{|c|c|c|c|c|}
\hline & Internists & Surgeons & Total & $p$ - value \\
\hline \multicolumn{3}{|c|}{ Hospital } & & \\
\hline $\mathrm{SH}$ & 21 & 48 & 69 & \multirow{4}{*}{0.1} \\
\hline EGH & 11 & 20 & 31 & \\
\hline $\mathrm{NH}$ & 13 & 10 & 23 & \\
\hline $\mathrm{AH}$ & 3 & 9 & 12 & \\
\hline Total & 48 & 87 & 135 & \\
\hline \multicolumn{5}{|c|}{ MD Grade } \\
\hline Consultant & 20 & 28 & 48 & \multirow{4}{*}{0.470} \\
\hline Specialist & 13 & 23 & 36 & \\
\hline Resident & 15 & 12 & 27 & \\
\hline GP & 2 & 2 & 4 & \\
\hline Total & 50 & 65 & 115 & \\
\hline \multicolumn{3}{|c|}{ Smoking habit } & & \\
\hline Smokers & 11 & 37 & 48 & \multirow{2}{*}{0.008} \\
\hline Non- smokers & 40 & 47 & 87 & \\
\hline Total & 51 & 84 & 135 & \\
\hline \multicolumn{5}{|c|}{ Number of cigarettes per day for all interviewed doctors } \\
\hline Mean $\pm($ std $)$ & $12.26 \pm 6.1$ & 15.2 & & \multirow{3}{*}{0.4} \\
\hline Minimum & 5 & 2 & & \\
\hline Maximum & 25 & 4 & & \\
\hline \multicolumn{5}{|c|}{ Duration of smoking for all interviewed doctors } \\
\hline Mean $\pm($ std $)$ & $19.7 \pm 5.8$ & 15.4 & & \multirow{3}{*}{0.2} \\
\hline Minimum & 13 & \multicolumn{2}{|c|}{2} & \\
\hline Maximum & 30 & \multicolumn{2}{|c|}{40} & \\
\hline
\end{tabular}

Gaza Strip Hospitals (SH: Al-Shifa Hospital; EGH: European Gaza Hospital; NH: Nasser Hospital; AH: Al-Aqsa Hospital).

habit. The questionnaire was completed during a face-toface interview by interviewers who were specially trained for the task. Before the administration of the questionnaire, all participants were informed about the aim of the study and assured confidentiality. The statement is in Arabic and English language and available upon request.

Consent for the study and its procedures was obtained from the Ministry of Health-Human Resources department, and data were then entered into Statistical Package for the Social Sciences software (SPSS version 23). Categorical variables were described using frequency table and Chi-Square tests were used to compare between groups, as relevant.

\section{Results}

The data show smoking to be common among practicing physicians in the Gaza strip around 38\% $(n=51)$. Of these, around $23 \%(n=12)$ were internists (internal medicine specialists) and $77 \%(n=39)$ were surgeons (Table 1$)$. Particularly troubling is that about $73 \%(n=37)$ of those smoked, reported also doing so in the hospital's public spaces, where patients or their relatives converge. Also, of note, $82 \%$ $(n=42)$ of physicians who smoke advise their patients to quit smoking, even though 59\% $(n=27)$ believe that their own smoking habit negatively impacts patients' adherence to their smoking cessation advice.

\section{Assessment of physicians' attitudes and knowledge regarding smoking cessation strategies}

Physicians' beliefs about perceived barriers to their patients' smoking cessation were centered on patients' 
personal deficits. Specifically, a little more than $81 \%(n=109)$ believed that "patients do not have the will to quit" and 68\% $(n=91)$ blamed patients' perceptions that "they are addicted and it is too hard to quit." These perceptions may contribute to physicians' overall reluctance to devote energy to smoking cessation efforts. Fully $61 \%(n=82)$ of physicians reported not spending any time talking to patients about the harms of smoking, with $27 \%(n=36)$ identifying a shortage of time as the reason that they choose to not counsel patients on smoking cessation. More disconcerting is that a fifth $(n=30)$ of physicians believe that advising patients is not their role (Table 2).

Finally, 97\% $(n=130)$ of the interviewed physicians were unaware of the comprehensive United States Public Health Service report offering clinical practice guidelines around tobacco use and dependence, which partly explains why only $34 \%(n=46)$ of physicians knew that nicotine dependence is a psychiatric disorder that necessitates a psychiatrist intervention (Table 3).

\section{Assessment of physicians' practices regarding smoking cessation strategies}

Regarding the management of smoking cessation, 33\% $(n=44)$ of physicians stated that saying "your disease cannot be improved unless you quit smoking" is enough as an intervention and $40 \%(n=54)$ of physicians provided counseling for their patients and spent some time conceiving them about the harms of smoking. Furthermore, only $15.6 \%$ $(n=21)$ referred their patients to a specialist and just six physicians gave their patients some pharmacological agents to help them to quit smoking. Only $22.2 \%(n=30)$ of physicians followed up with their patients to check if they are following their smoking cessation advice (Table 4).

\section{Discussion}

Data from this investigation revealed some troubling patterns as it relates to smoking cessation efforts in the Gaza Strip. First, nearly $2 / 5^{\text {th }}$ of this sample of physicians in Gaza Strip reported that they are smokers; well more than double the rate found in the general Palestinian population in the same area (15\%) [3]. In fact, the rate of smoking among Palestinian physicians in Gaza strip is greater than their counterparts in China (23\%) [4], Israel (16.7\%) [12], the USA (4\%) [13] and the UK (6.8\%) [4].

The majority of physicians in Gaza who smoke also reported doing so in the hospital's public spaces (72.5\%). This compares poorly with a previous report of smoking in hospital public spaces among West Bank smoker physicians (58.2\%) [14].

Possible explanations of Gaza strip physicians' greater propensity to smoke, as compared to the general population, are the occupational stress they endure, and the reliance on smoking as a (problematic) coping mechanism. The absence of strict regulations that control smoking in public and medical facilities exacerbates the problem. Moreover, the lack of trained specialists to deal with nicotine use disorder discourages smokers to look for consultation.

Table 2: Smoking cessation barriers.

\begin{tabular}{|c|c|c|c|c|c|}
\hline \multirow[t]{2}{*}{ Item } & \multirow[t]{2}{*}{ Total no (\%) } & \multicolumn{2}{|c|}{ Internists } & \multicolumn{2}{|c|}{ Surgeons } \\
\hline & & Smokers & Non-smokers & Smokers & Non-smokers \\
\hline Advising patients is not my role. & $30(22 \%)$ & $8(26.6 \%)$ & $3(10 \%)$ & $12(40 \%)$ & $7(23.3 \%)$ \\
\hline I do not have enough time to advice. & $36(27 \%)$ & $2(5.5 \%)$ & $12(33.3 \%)$ & $15(41.6)$ & $7(19.4 \%)$ \\
\hline I think patients do not have a will to quit. & $109(81 \%)$ & $8(7.3 \%)$ & $29(26.6 \%)$ & $35(32.1 \%)$ & $37(33.9 \%)$ \\
\hline I do not spend time to convince patients to quit; I just give them the advice. & $89(66 \%)$ & $10(11.2 \%)$ & $24(26.9 \%)$ & $25(28 \%)$ & $30(33.7 \%)$ \\
\hline The patients believe that they can quit at any time and they are not addicted. & $79(59 \%)$ & $7(8.8 \%)$ & $19(24 \%)$ & $23(29.1 \%)$ & $30(38 \%)$ \\
\hline The patients believe that use of cessation assistance is a sign of weakness "help is not necessary". & $84(62 \%)$ & $4(4.7 \%)$ & $23(27.4 \%)$ & $28(33.3 \%)$ & $29(34.5 \%)$ \\
\hline The patients believe that they are too addicted and it is too hard to quit. & $91(67 \%)$ & $10(11 \%)$ & $29(31.8 \%)$ & $25(27.5 \%)$ & $27(29.7 \%)$ \\
\hline The patients believe that it is too late to quit and they might not benefit so why bother. & $72(53 \%)$ & $7(9.7 \%)$ & $22(30.5 \%)$ & $22(30.5 \%)$ & $21(29.1 \%)$ \\
\hline
\end{tabular}

Table 3: Physicians' knowledge regarding smoking Habit Assessment.

\begin{tabular}{|c|c|c|c|c|c|}
\hline \multirow[t]{2}{*}{ Item } & \multirow[t]{2}{*}{ Total no (\%) } & \multicolumn{2}{|c|}{ Internists } & \multicolumn{2}{|c|}{ Surgeons } \\
\hline & & Smokers & Non-smokers & Smokers & Non-smokers \\
\hline I know what $5 \mathrm{~A}$ structure for smoking cessation is. & $4(3 \%)$ & $0(0 \%)$ & $2(50 \%)$ & $1(25 \%)$ & $1(25 \%)$ \\
\hline I think nicotine dependence is a psychiatric disorder that requires specialist intervention. & $46(34 \%)$ & $2(4.3 \%)$ & $17(26.1 \%)$ & $10(21.7 \%)$ & $17(26.1 \%)$ \\
\hline
\end{tabular}

Table 4: Physicians' practices regarding smoking cessation strategies current management of smoking cessation.

\begin{tabular}{|c|c|c|c|c|c|}
\hline \multirow[t]{2}{*}{ Item } & \multirow[t]{2}{*}{ Total no (\%) } & \multicolumn{2}{|c|}{ Internists } & \multicolumn{2}{|c|}{ Surgeons } \\
\hline & & Smokers & Non-smokers & Smokers & $\begin{array}{c}\text { Non- } \\
\text { smokers }\end{array}$ \\
\hline I think that saying "your disease cannot be improved unless you quit smoking" is enough. & $44(33 \%)$ & $5(11.4 \%)$ & $11(25 \%)$ & $16(36.4 \%)$ & $12(27.3 \%)$ \\
\hline I counsel all my patients and spend time with them to convince and show them the harms of smoking. & $54(40 \%)$ & $2(3.7 \%)$ & $20(37 \%)$ & $14(25.9 \%)$ & $18(33.3 \%)$ \\
\hline I refer them to a specialist. & $21(16 \%)$ & $0(0 \%)$ & $9(42.8 \%)$ & $7(33.3 \%)$ & $5(23.8 \%)$ \\
\hline I do behavioral therapy with the patients. & $46(34 \%)$ & $3(6.52 \%)$ & $15(32.6 \%)$ & $12(26.1 \%)$ & $16(34.8 \%)$ \\
\hline I give them pharmacological agents. & $6(4 \%)$ & $1(16.6 \%)$ & $1(16.6 \%)$ & $2(33.3 \%)$ & $2(33.3 \%)$ \\
\hline I follow up with my patients to make sure they apply my advice. & $30(22 \%)$ & $2(6.6 \%)$ & $12(40 \%)$ & $6(20 \%)$ & $10(33.3 \%)$ \\
\hline
\end{tabular}


In spite of the relatively high prevalence of smoking among Gaza strip physicians, the self-reported rate of advising patients against smoking was higher in Gaza (82.4\%) than in some other countries in which physician-smoking rates were lower (e.g., China, 64\%) [4]. Curiously, a large percentage of interviewed physicians in this sample believed that patients who smoke do not have the will to stop doing so. In addition to that, many physicians reported a lack of time as a primary reason that prevents them from engaging in active smoking cessation efforts beyond simplistic counseling.

In the United States, the 5As framework AAsk about tobacco use, Advise quitting, Assess readiness to quit, Assist smokers ready to quit, Arrange follow-up treatment $\}$ has been recommended in national guidelines since 2008 and has been updated by US Preventive Services Task Force guidelines to evaluate smoking habit and cessation plan [15]. Unfortunately, this guideline is totally ignored in local practice in the Gaza strip as only (3\%) of physicians were aware of the report or its recommendations.

Nicotine use is recognized as a substance use disorder by Diagnostic and Statistical Manual of Mental Disorders, $5^{\text {th }}$ Edition [16], this diagnosis of nicotine use disorder was acknowledged by a third of the interviewed physicians versus (91\%) of the physicians who were internationally surveyed [17].

The management of smoking cessation was so poor as only $(15.5 \%)$ of physicians refer patients to specialists for most of the physicians believe that nicotine dependence is not a psychiatric disorder and there are no specialized centers to treat that type of dependence. Moreover, the patients only rarely (4.4\%) prescribed pharmacological agents i.e. nicotine replacement therapy, varenicline, or bupropion and this result is nearly similar to that found in Nigeria (2.6\%) [18] and China (6.6\%) [4], but it is strictly far away from the result of the international survey which stated that $(23 \%)$ of smoker physicians and $(30 \%)$ of non-smoker physicians prescribe pharmacological agents for their smoker patients [17].

Follow up appointments were poorly arranged to check if the patients follow their doctor's advice in the local practice (22.2\%) but it is better than Nigeria (17.4\%) [18]. And worse than that found in the international survey which stated that nonsmoker physicians follow up (23\%) more than smokers (18.6\%) [17].

\section{Conclusion}

Smoking is a common habit among Gaza strip physicians; making the problem worse is that most of them smoke in hospital's public spaces, where their patients can see them, thus nullifying the credibility of smoking cessation advice from those same physicians. The data from this investigation also reveal several obstacles to a broader smoking cessation program, including physician problematic beliefs about the patients' will, inadequate physician knowledge regarding smoking cessation guidelines, and a local health system that does not classify smoking as a health problem. Systematic and comprehensive educational programs directed for physicians and instituted at the organizational level in hospitals must be initiated across the public health sector in Gaza to fight this habit and apply the role of primary prevention to decrease the incidence of smokers and smoking harms.

\section{References}

1. Forouzanfar $\mathrm{MH}$, Afshin A, Alexander LT, Biryukov S, Brauer M, et al. Global, regional, and national comparative risk assessment of 79 behavioural, environmental and occupational, and metabolic risks or clusters of risks, 1990-2015: a systematic analysis for the Global Burden of Disease Study 2015. Lancet. 2016; 388: 1659-1724.

PubMed: https://www.ncbi.nlm.nih.gov/pubmed/27733284

2. WHO Regional Office for Europe. Tobacco control in the WHO European Region. 2017.

3. PCBS. Palestinian Family Survey 2010 Final Report. Palest Cent Bur Stat Ramallah-Palestine. 2013.

4. Jiang $Y$, Ong MK, Tong EK, Yang $Y, \operatorname{Nan} Y$, et al. Chinese Physicians and Their Smoking Knowledge, Attitudes, and Practices. Am J Prev Med. 2007; 33: 15-22.

PubMed: https://www.ncbi.nlm.nih.gov/pubmed/17572306

5. Abdullah AS, Stillman FA, Yang L, Luo H, Zhang Z, et al. Tobacco use and smoking cessation practices among physicians in developing countries: A literature review (1987-2010). Int J Environ Res Public Health. 2013; 11: 429-455.

PubMed: https://www.ncbi.nlm.nih.gov/pubmed/24380976

6. Dülger S, Doğan C, Dikiş ÖŞ, Yıldırım E, Tapan U, et al. Analysis of the Role of Physicians in the Cessation of Cigarette Smoking Based on Medical Specialization. Clinics. 2018; 73: 347.

PubMed: https://www.ncbi.nlm.nih.gov/pubmed/29694604

7. McCrabb S, Baker AL, Attia J, Balogh ZJ, Lott N, et al. Hospital smokefree policy: compliance, enforcement, and practices. A staff survey in two large public hospitals in Australia. Int $\mathrm{J}$ Environ Res Public Health. 2017; 14: 1358.

PubMed: https://www.ncbi.nlm.nih.gov/pubmed/29117149

8. World Health Organization, Abdullah AS, Stillman FA, Yang L, Luo H, et al. Heart disease and stroke statistics-2018 update: a report from the American Heart Association. Circulation. 2018; 3: 1-7. PubMed: https://www.ncbi.nlm.nih.gov/pubmed/29386200

9. Stead LF, Buitrago D, Preciado N, Sanchez G, Hartmann-Boyce J, et al Physician advice for smoking cessation. Cochrane Database Syst Rev. John Wiley \& Sons, Ltd; 2013.

10. World Health Organization. WHO report on the global tobacco epidemic, 2011: warning about the dangers of tobacco. 2011; 152: 1-152.

11. Supporting smoking cessation: a guide for health professionals. Royal Australian College of General Practitioners (RACGP). 2011.

12. Shkedy Y, Feinmesser RM, Mizrachi A. Smoking habits among Israeli hospital doctors: a survey and historical review. Isr Med Assoc J. 2013; 15: 339-341.

PubMed: https://www.ncbi.nlm.nih.gov/pubmed/23943976

13. Nelson DE, Giovino GA, Emont SL, Brackbill R, Cameron LL, et al. Trends in cigarette smoking among US physicians and nurses. JAMA. 1994; 271: 1273-1275.

PubMed: https://www.ncbi.nlm.nih.gov/pubmed/8151902 
14. Mizher IY, Fawaqa SI, Sweileh WM. Prevalence and personal attitudes towards tobacco smoking among Palestinian healthcare professionals: a cross-sectional study. Addict Sci Clin Pract. 2018; 13: 17.

PubMed: https://www.ncbi.nlm.nih.gov/pubmed/30053911

15. AL S, for the U.S. Preventive Services Task Force. Behavioral and pharmacotherapy interventions for tobacco smoking cessation in adults, including pregnant women: U.S. preventive services task force recommendation statement. Ann Intern Med. 2015; 163: 622-634.

16. American Psychiatric Association. Diagnostic and Statistical Manual of Mental Disorders. Fifth edit. Arlington, VA: American Psychiatric Association. 2013.

17. Pipe A, Sorensen M, Reid R. Physician smoking status, attitudes toward smoking, and cessation advice to patients: An international survey. Patient Educ Couns. 2009; 74: 118-123.

PubMed: https://www.ncbi.nlm.nih.gov/pubmed/18774670

18. Desalu 0O, Adekoya AO, Elegbede AO, Dosunmu A, Kolawole TF, et al. Knowledge of and practices related to smoking cessation among physicians in Nigeria. J Bras Pneumol. 2009; 35: 1198-1203. PubMed: https://www.ncbi.nlm.nih.gov/pubmed/20126921 